\title{
Physiotherapy Students' and Practice Educators' Experiences of Using Placements Passports: A Tool to Enhance Collaboration on Placement
}

\author{
*Sarah-Jane Ryan ${ }^{a}$ \& Jane Morris ${ }^{a}$ \\ a: University of Brighton, United Kingdom
}

\begin{abstract}
Integral to physiotherapy students' study are their practice placements. Placements form a mandatory part of students' programmes of study. Practice learning is seen as an essential component of the curricula and as such is a key element of the students' learning and development. The UK health service, which continues to provide the majority of practice learning opportunities for healthcare students, is experiencing unprecedented demand on services. Practice educators are reporting increasing pressure to maintain service provision whilst trying to support students in the practice setting. To maximise learning on placement, the placement passport was developed. This aims to support a more collaborative approach to the student's learning in practice, by promoting a partnership between the practice educator and the student, and by encouraging and enabling the students to develop their skills of selfevaluation and self-directed learning, but also giving the practice educator the opportunity to try to tailor the experience to the student's needs and wants. This study aims to explore students' and practice educators' experiences of using a placement passport in physiotherapy education. Five students and four practice educators attended one-off focus groups to explore their experiences. Findings suggested that the passport is a tool to support collaborative approaches to students' learning, helping students and practice educators to bridge the gap between academia and the reality of practice. It also provided both with the opportunity to begin early dialogue around the students' and practice educators' expectations of the practice placement while acknowledging prior learning and development.
\end{abstract}

Keywords: collaboration; inclusivity; physiotherapy; practice placement

\section{Background}

Health professional physiotherapy students undertake practice placements in a range of practice settings. Such placements, which are facilitated and assessed by practice educators, form a mandatory and integral part of their programme of study and are essential to prepare them for their future role as health professionals $n$ the United Kingdom (Health and Care Professions Council, 2018). They are considered necessary for making student learning and curriculum more relevant, facilitating professional learning and self-development (Trede et. al., 2012; Webster-Wright, 2009). Placements aim to prepare students for

*Corresponding Author: Sarah-Jane Ryan, School of Health Sciences, University of Brighton, 49, Darley Road, Eastbourne, BN20 7UR United Kingdom

Email: S.J.Ryan@brighton.ac.uk

Journal URL: https://publications.coventry.ac.uk/index.php/pblh

Ryan, S. -J., \& Morris, J. (2020). Physiotherapy students' and practice educators' experiences of using placements passports: a tool to enhance collaboration on placement. International Journal of Practice-based Learning in Health and Social Care, 8(1), 31-46. https://doi.org/10.18552/ijpblhsc.v8i1.540

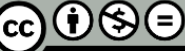

BY NC ND (C) 2020 Sarah-Jane Ryan \& Jane Morris. This Open Access article is distributed under the terms of the Creative Commons Attribution Attribution-Non-Commercial No Derivatives 4.0 International License (https://creativecommons.org/licenses/by-nc-nd/4.0/ ), which permits unrestricted non-commercial use, distribution, and reproduction in any medium, provided the original work is properly cited and is unaltered. 
future professional practice by enhancing the development of their professional identity (Dall'Alba, 2009).

It is now recognised that today's health professional graduates need to be 'work ready' (Cooper et. al., 2010), with the ability to practise safely and autonomously, whilst responding to the complex demands of an ever-changing health and social care landscape (Cross, 2013) and to concurrent changes in service delivery (Harvey-Lloyd et. al., 2019). Therefore, in addition to profession-specific knowledge and skills, students need to develop skills of leadership and self-evaluation (Boud, 2015) and be caring and personcentred in their approaches (Schmitt et. al., 2012). This can be demanding for students and practice educators alike in the current NHS environment with its stretched resources (West, 2019). Whilst the benefits of learning in practice are well recognised (Cooper et. al., 2010; Delany \& Bragge, 2009). It is acknowledged that in contemporary practice learning environments, practice educators face increasing demands on their time with ever-changing roles. As a result, their ability to reserve time for supporting students on placement may be increasingly tested (Mooney et. al., 2008). As Cross (2013) suggests:

The challenges for hard-pressed practitioners are equally daunting... the complexity and ever evolving nature of health and social care systems have reshaped professions and redefined the various roles of practitioners and educators alike (p. 29)

Faced with these challenges, it is essential that students are well prepared for learning and working in practice. This validates the need for a tool to support this transition.

In practice learning environments, a range of learning and teaching approaches are used to enable students and practice educators to work together to ensure that individual student learning needs are met and that patient safety and quality of care are given the highest priority (Cross et al., 2006). One of the commonly used tools that facilitates student learning during health professional placements is the negotiated learning agreement or learning contract (Barrington \& Street, 2009; Cross et al., 2006; Matheson, 2003). This tool provides a useful framework for promoting discussion between students and their practice educators, encouraging the identification of learning needs and the establishment of learning outcomes and, in discussion, of evidence used to assess individual learning outcomes (Barrington \& Street, 2009; Chan \& Chien, 2000; Cross et al., 2006). However, research suggests that students, especially those on early placements, find it challenging to identify their learning needs and establish realistic as opposed to impractical learning goals (Chan \& Chien, 2000; Matheson, 2003). In addition, increasing numbers of students entering health professional courses have additional learning needs (Aronin \& Smith, 2016). It is therefore essential that they are fully supported in both campus and practice settings to ensure that they experience high-quality learning experiences that promote inclusive practice (Griffiths et. al., 2010). Although disclosure of additional needs has always been promoted (Equality Act, 2010), students may initially be reluctant to reveal their needs as they do not wish to be treated as a 'special case' (Morris \& Turnbull, 2006). As a result, valuable time may be lost on placements whilst practice educators, who are also busy practitioners, struggle to identify why students are finding aspects of their placement challenging. Consequently, time that could have been used to make adjustments to support students may be lost, resulting in reduced learning opportunities. Students also noted that not feeling cared for themselves could impact upon their own ability to care for others (Greenfield et. al., 2008).

As educators with many years of experience of facilitating and assessing student learning on campus and in practice, we recognised the increasing need to support students during their transition from campusbased learning into practice. We have developed a placement passport (Appendix A) that has been designed to encourage students to disclose their learning needs, especially any additional needs, prior to starting a placement. Students complete and subsequently update the passport with the support of their academic personal tutor before sharing it with their practice educators prior to each placement. This is an integral and essential part of their pre-placement preparation. Our aim was to facilitate disclosure, promoting equality of opportunity, and to encourage students to identify both their strengths and areas for development that help in the negotiation phase of learning agreements. Thus the relationship between practice educator and student may develop as early as possible, enabling the student to feel cared for and be an integral member of the team for the duration of the placement, potentially impacting positively on patient care. In this article, we aim to add to the literature on practice-based education by providing some insight into the experiences of physiotherapy students and practice educators who used the placement passport. 
Research question: What are the experiences of physiotherapy students and practice educators of using the placement passport during practice-based education?

\section{Method}

Ethical approval was sought and gained from the University of Brighton's School of Health Sciences Research Ethics Panel. Both student and practice educator participants were invited to partake in focus groups through purposive sampling (Creswell, 2007). It has been suggested that focus groups preserve the individual experience while stimulating new perspectives through discussion (Bradbury-Jones et. al., 2009). An email from an independent administrator was sent to all final-year students on the BSc (Hons) Physiotherapy and MSc Rehabilitation Sciences (pre-registration) courses at the University of Brighton. To recruit active practice educators, an email was sent to the alumni of the pre-registration and postregistration physiotherapy programmes. Contact details of the researchers were included for further questions in relation to this research or to allow potential participants to express interest in taking part. The inclusion criterion for student participants was current final-year study on either the BSc (Hons) Physiotherapy programme or MSc Rehabilitation Science (pre-reg) programme to ensure experience of using placement passports both before and during placements. The inclusion criteria for practice educator participants were: current practice educator status for at least one of the programmes, and experience of working with placement passports as part of their role.

A qualitative interpretative approach was used (Merriam, 2009). Open-ended questions allowed the participants to have the freedom to express their views, whilst the topic guide (Appendix B) enabled the researchers to maintain a focus on the research question. Focus groups were facilitated by the researchers, digitally recorded and the audio recordings were transcribed verbatim by a research assistant. Transcripts were kept in a password-protected electronic document accessible only to the researchers. The transcript was fully anonymised before analysis. Thematic analysis (Braun \& Clarke, 2006) was used to interpret and analyse the data. This involved the researchers becoming familiar with the data, generating initial codes, searching, reviewing, defining and naming the themes, and finally the production of the report (Braun \& Clarke, 2006). Both researchers undertook a separate analysis of the data supported by their individual reflexivity to ensure rigour in the analysis phase. At the next stage, analysis of the data was shared and agreed before the final themes emerged. This required a constant shift back and forward between each of these stages ensuring the analysis phase was both flexible and rigorous (Nicholls, 2009). As both researchers were members of academic staff at the same higher education institution (HEI) and had been instrumental in the development of the passport, recognition of our own position as insider researchers was essential. However, there is always the concern that there is a loss of objectivity and that greater familiarity can risk assumptions being made (Greene, 2014). To minimise this, during the period of data collection, neither researcher was directly involved in student assessment or support on practice placement.

\section{Findings}

Five students ( 3 female and 2 male) participated in one focus group and four practice educators ( 3 female and 1 male) participated in another. Findings from the study suggest that students and practice educators found the passport a useful tool that facilitates transition into practice, promotes inclusivity, and may foster a more reflective and proactive approach to learning in practice. Student participants identified the need for all practice educators to acknowledge and review the content of their passports, demonstrating commitment to the process. Two main themes emerged from the data: (1) Fostering transition; and (2) Valuing and acknowledging. Both these themes had several sub-themes, outlined below.

\section{Fostering transition: Bridging the gap}

Practice educators talked about the benefits of the passport when students proactively engaged with the tool. It enabled students to identify their strengths and areas for development before the start of the placement. This active engagement seemed to provide a platform from which a more holistic approach to placement learning could evolve. 
I think it gives students a platform before they come to placement to sort of showcase what their strengths are, and what their weaknesses are, or areas for development, as long as they're accurate and true to themselves in that respect. (Practice Educator 4)

The platform that the passport provided was deemed to be useful if students were open and transparent about their learning needs. Practice educators recognised that some students adopted a mechanistic approach, seeing it as a box-ticking exercise. However, when students proactively engaged with the passport, an effective plan of action and a holistic approach to the whole learning experience was established.

Some see it as a tick box exercise... but for those who put effort in... there is a plan of action for the whole placement, learning needs, development needs and teaching sessions all incorporated. (Practice Educator 3)

\section{Fostering transition: A tool for reflection}

Through engagement with the passport, students' ability to develop the skills of self-reflection was promoted. The process of completing the passport encouraged them to identify their learning needs and opportunities for learning in advance. It also prevented educators from putting students under pressure at the start of the placement by expecting students to identify their needs in a rushed way due to time constraints. It was felt that this often promoted the establishment of a relationship, allowing the student to feel cared for, and more integral to the team.

It gives them a bit of a way of reflection from their previous placements, rather than just trying to think of all of the other things all at once, if they write it down, they can go back, they can have a look and then they can let you know what they want before you meet... before they get there... it helps me to get a sense of them, of how they tick. (Practice Educator 2)

I suppose it gives them a chance to think about who I am, what I have done on my previous placements, if they actually refer to it, it makes me feel like they have read it, they actually care about who I am a bit more rather than just being their next student... (Student 1)

Students also acknowledged the value of this reflective process that seemed to help them make links with other placements and feel like they could settle quicker into a placement. Engagement with the passport before each placement encouraged them to think about their continuous development in practice.

You're also kind of re-seeing it each time you do a placement, what you've learned and how you've kind of changed and what you've done for action plans, through the reflections of the other placements and what you've done. I found that aspect quite good, just er... and just keep on building from there as a continuous like development... just felt it helped me to settle into the placement quicker as I knew what I wanted and what I needed from my educator. (Student 2)

\section{Fostering transition: Advanced planning}

Both practice educators and students found use of the passport helped them to plan in advance. In addition, practice educators found the passport useful in helping them to identify other team members who could contribute to a student's learning on placement; this allowed the team to think about the best fit for the student to support and care for that student's learning experience:

it helps us to determine which staff member should get which student, depending on what they're highlighting as their strengths and weaknesses and what environment fits in there better, so it helps us as well (Practice Educator 4)

The benefit of advanced planning was also acknowledged by one of the student participants, who remained mindful of the demands placed on practice educators when organising placements:

I think it's beneficial for the educators to have that insight because it takes some planning and organisation to arrange different things if I want to look. (Student 2) 


\section{Fostering transition: Communication mismatch - to reveal or not to reveal?}

This sub-theme reflects the difficulties faced by a practice educator and a student, if a mismatch in communication occurs, detracting from a more collaborative process where students openly share their needs in advance. In contrast to the benefits identified above, practice educators talked about the challenge they faced when students failed to identify their learning needs and areas for development on their passports:

The only issue I had was with one student where his passport didn't match up with actually how he was and that came as quite a surprise because I was expecting this all-singing, alldancing student to come in through the door and that's not what my experience was.

(Practice Educator 4)

As a result of the disparity, progress on placement was delayed as the student's educator struggled to tailor their approach to meet the students' actual needs. This highlights the importance of students being open and honest when sharing their placement passports with their educators. Participation in the focus group enabled educators to share strategies for managing mismatches in disclosure; they agreed that students should be made aware of any discrepancy early in the placement.

The last one I had I did highlight it and that was the first time I had experienced that [mismatch]. If it happens in the future, I would definitely bring it up sooner, because it's for the student's own good basically, because... we can sort of get things sort of a little clearer and have that better communication, I want them to know I care that they do ok. (Practice Educator 3)

Student participants also acknowledged a mismatch in the way that areas for development were communicated. They suggested that a student might be deterred from identifying weaknesses or areas for development if educators engaged in the practice of pre-judging, focussing solely on a student's weakness during the placement.

I think there was an element of... pre-judging, that's a harsh word, but speaking of my weaknesses, sort of points of development, because I'm also an overthinker and in both my placements I feel like the educators just grabbed on to that and that was a big part of my feedback in both... in both my placements, and they were... well you know you really have to work on this overthinking. (Student 3 )

\section{Valuing and acknowledging: Caring who I am}

Student participants identified the need for practice educators to acknowledge and review the content of their passports, demonstrating commitment to the process. Both practice educators and students suggested that the whole process could be enhanced if educators and students adopted a more reciprocal humanistic approach.

If they do read it and they address it to you looking at it, how we may be able to kind of accommodate for this even before I come into contact, so I feel that's kind of more beneficial and maybe um... kind of more caring towards like what you want, what you want to learn and... from that placement, and kind of what you are as a person... a human connection. (Student 3)

Student participants also reflected on the value of the human connection between student and educator. They welcomed the practice of practice educators who, having reviewed the passport, responded in a preplacement email and tried to accommodate their learning needs. This acknowledgement was important to students acknowledging them as a person and not just a name. It meant they felt like they were cared about.

if they actually refer to it, it makes me feel like they have read it, they actually care about who I am a bit more rather than just being their next student. (Student 1) 
In contrast to those educators who saw the placement passport as merely a box-ticking exercise, educators who took an interest in the student's passport appeared to demonstrate commitment to facilitating learning and seeing the student as a person.

\section{Valuing and acknowledging: $A$ bit of an ice breaker}

Feeling valued through having the passport acknowledged was something that all students mentioned. It was felt that placements are hard but especially so for those less confident. The passport provides a link, an ice breaker as such.

I mean everyone's nervous when they go out on placement, but particularly people who are really quite shy, to see... even if they see an interest in their educator, that they feel like they have a little bit of common ground about, it kind of breaks that ice down a little bit perhaps. (Student 2)

Through acknowledgement of the passport and the student's pending arrival, practice educators helped them to feel part of the team that they were about to join. This acknowledgement of the student's passport and learning needs was also felt to be useful in developing common ground, between student and educator. In contrast, some students had experience of practice educators who failed to acknowledge the passport.

because I think some of them receive it, and some give it importance and some of them don't, not really addressing it... you kind of wonder why bother putting the effort in, it's there to tell them about you but if they can't be bothered... (Student 1)

\section{Valuing and acknowledging: Feeding forward}

While participants acknowledged the benefits of the placement passport, focus group discussion enabled practice educators and students to identify ways of enhancing the process of feeding forward into future practice. Practice educators recognised that some students wanted to give a good impression before arrival on placement and might be reluctant to reveal their needs and areas for development. As a result, their passport felt more like a job application, than a reflection on their learning.

they want to be all-singing, all-dancing, you know. (Practice Educator 5)

they don't just write it like a job application, they actually know what we want to hear and what we're looking for and why we want to know it. (Practice Educator 4)

Practice educators recognised that pre-placement preparation on campus could be improved, if they were invited by academics to talk to students about what they (the practice educators) were looking for in a passport. As a result, this practice has now been integrated into current pre-placement preparation.

I don't know if the students already get it, but sort of some insight from educators about what we look for in the passports, so that they... they don't just write it like a job application, they actually know what we want to hear and what we're looking for. (Practice Educator 1)

In addition, educators talked about the way in which the placement passport feeds forward to future placements and generated links to future employability.

The last student I had ... I was on NHS Jobs anyway, because I... we were recruiting at the time, and she said oh can I have a little look and we talked about her passport,... and she actually said oh wait a minute I'll show you my passport..., I've written the bit for the next placement, I was able to help her for her next one. (Practice Educator 2)

Student participants also identified opportunities for developing the passport process for the future.

Yeah for me another thing was probably that, and correct me if I'm wrong but I don't think there's a systematic way to deal with these passports at the educators' end, so that's why I think we have such different... differing experiences in terms of what they have done.

(Student 4) 
Students' reflected on the lack of consistency in the way practice educators engaged with the passports. They suggested that the process could be tightened if, on receipt of the passport, practice educators were prompted to review it and acknowledge receipt.

\section{Discussion}

This study explored practice educators' and students' experiences of using a placement passport. Use of the placement passport enabled practice educators to gain insight into a student's needs and to make the most of individualising learning opportunities. This advanced preparation has potential advantages for educators who continually strive to balance the needs of students alongside the frenetic demands of service delivery (Department of Health, 2013) whilst promoting inclusivity. Inclusive practice is an approach to learning and teaching that ensures that the diverse learning needs of students are met, and that students can fully engage in each learning experience (Thomas \& May, 2010). Such an approach is fundamental to ensure that all students experience a high-quality learning experience on campus and in practice. Through revisiting the passport, and reflecting on their practice after each placement, students seemed to gain insight into how their practice had changed. This in turn enabled them to build on their experience and to design action plans, feeding forward into future placements and their practice. The value of reflective practice in supporting students in practice was acknowledged by $\underline{\text { Smith and Trede }}$ (2013, p. 636), who identified the benefits students gained from active engagement in reflection on "real life" practice during their transition from student to novice practitioner. The importance of reflective practice in informing ongoing professional development of health professionals is seen to be essential for equipping students and practitioners with the skills necessary for thinking about and evaluating their own practice (Bradbury-Jones et al., 2009; Clouder, 2000). It also helps to prepare students for practising effectively and flexibly within contemporary practice environments (Trede et. al., 2012). In the current study, practice educators identified the essential need for students to reflect on their own practice and to recognise their limitations, attributes recognised by Chipchase et al. (2012). Students and educators recognised that the introduction of the passport enabled practice educators who are constantly managing time constraints to prepare in advance, and where possible to match students with educators to optimise their learning opportunities.

As the findings suggest, there are inevitably challenges faced by practice educators and students when students are sharing information that could potentially influence the assessment process and, ultimately, a student's grade. The potential for pre-judgement, linked to bias, was a concern expressed by several student participants. Good practice in assessment of practice-based education (Cross et al., 2006) highlights the need for practice educators to recognise the challenges and potential bias in the assessment process. The importance of practice educators reflecting on their own practice and potential bias is deemed essential, as it can influence assessment of students in a negative or positive way (Keating et al., 2009). Delany and Molloy (2009) and Morris (2011) identified the need for practice educators to adopt a more collaborative approach to assessment that has the potential to help students more openly share strengths and areas for development.

Student participants in the current study valued the human connection that developed when the passport was adopted and used effectively by practice educators. This was deemed important to students, who wanted to feel accepted, cared for and recognised as a person first and a student second. Hockings (2010) identified the value of educators who recognise students as people, ensuring they each gain the maximum from their experiences. A reciprocal relationship was achieved when practice educators acknowledged students' learning needs and recognised them as individuals. This in turn contributed to the students' "sense of being", a key factor in the development of professional identity as recognised by the seminal work of Gloria Dall'Alba who identified the importance of the "self" in the transformation period when students are "being" and "becoming" professionals (Dall'Alba, 2009, p. 39). It may be argued that this construct of caring for the student, in a way that promotes human connection, mirrors person-centred practice and as a result should be a key element of practice-based education. Such an approach may guide the student towards the values of care and a person-centred approach that they need to adopt in their role as future health professionals. To put this in context, Nicholls and Holmes (2012, p. 462) emphasise that "if physiotherapists are to be able to meet the complex, multifaceted demands of the population, then they must develop practice models that cater for much greater inclusiveness and diversity." West (2019) challenges the importance of caring in the current NHS. He argues that all staff need to belong and that in this belonging there is a desire to care and be cared for. Physiotherapy students need to be supported to 
marry the need for skill acquisition with developing a caring approach to their patients. Within physiotherapy, Dahl-Michelsen (2015) raises some interesting discussion around whether the profession sees itself as curing or caring. This conflict continues to be grappled with by the profession and in education, in developing graduates that are adaptable and ready to engage in all areas of practice especially those that focus more on caring, e.g. older people rehabilitation (Grace \& Trede, 2013; Nicholls \& Gibson, 2010)

The importance of a good educator/student relationship in contributing to a positive placement learning experience is widely acknowledged (Clouder \& Adefila, 2014; Cross, 1998; Rodger et al., 2011). These relationships in the practice learning environment are essential to learning in practice, and relationships built on trust between practice educators and students are deemed to be key to a successful learning experience (Cross et al., 2006; Hartigan-Rogers et. al., 2007). Findings from our study suggest that students' active engagement with the passport may facilitate a more proactive approach and, in some cases, demonstrate a commitment to the learning process. These findings resonate with research by Clouder and Adefila (2014, p. 56) who drew on the metaphor of a "gift exchange" in order to conceptualise the "dynamic relationship" between practice educator and student. Findings from their study showed that when students and practice educators play an active part in the learning process, a reciprocal relationship is established which in turn contributes to a collaborative learning experience. Engagement through partnership was also identified in the seminal work of Healey et. al. (2014), who highlighted its value in building student confidence and in promoting learning achievement and gain.

Whilst our findings focussed mainly on the value of student engagement with the passport, practice educators acknowledged that they need to take a more proactive approach when they receive the passport. They recognised that this would help to establish the educator/student relationship, and promote partnership in the learning process, easing a student's transition into practice. Wenger's research into communities of practice acknowledged the importance of students "being able (and allowed) to engage productively with others in the community" (Wenger et. al., 2011, p. 2). As students must engage in a variety of different practice communities during their pre-registration, pre-placement engagement may ease their transition into each new, and often very different practice learning community.

Practice educators also saw the opportunity of reciprocal pre-placement engagement as a way of sharing their own experience of 'being a student'. This exchange of authentic experience is valued by students and is felt to enhance the trust between practice educator and student as the educator is "viewed in a more human light" (McAllister \& Lincoln, 2004; Morris, 2011, p. 141). Educators who acknowledge challenges faced by students and remember what it was like to be a student, are felt to develop more successful relationships with students on placement (Molloy, 2009; Rodger et al., 2011). Indeed, students may be more inclined to share their learning needs and past experiences openly when on placement with an educator who can identify with their position as a student. This is felt to promote a more collaborative approach and engage students more actively in the learning process (Morris, 2011). Lindquist et al. (2006) found that the demand for a variety of abilities and competencies is increasing for new graduates and that educators are challenged to support students' earlier development into roles that would traditionally be considered later in careers. Adoption of the passport enabled some educators to review the tool with students which in turn fed into future placements and stimulated discussion about their future roles as graduates.

\section{Study limitations and future work}

This was a small-scale qualitative study. All student participants were from one discipline in one higher education institute, and practice educators mainly had students from this same institute. However, findings may resonate with other health professional students and practice educators both in the UK and internationally, maximising learning opportunities in practice in today's frenetic health and social care environment. Both the researchers are members of the academic team which may have impacted on the openness of the discussion in the focus groups. Morgan (1997) acknowledges that all facilitators' behaviour will play a role in the interface of any focus group; however, both researchers fully immersed themselves in reflective practice acknowledging their own voice (Jackson \& Mazzei, 2009) and also in the analysis phase to explore the depth and breadth of the data shared (Braun \& Clarke, 2006). 


\section{Conclusion}

Campus and practice curricula are designed to develop criticality that fosters independence. However, demonstrating this in an appropriate way to practice educators to get the most from practice learning experiences is where the research suggests the placement passport can assist. The passport not only allows the student to explore their own blind spots and have the confidence to share, but also encourages the practice educator to care for the individual development of the student. In doing this, they explore their own practice including their possible biases. Physiotherapists, like other health professionals, are continually developing and challenging their practice. Central to student development is the need to support and value them for successful patient-centred care.

\section{Acknowledgements}

The authors wish to thank the physiotherapy students and practice educators who generously gave up their time to take part in the study.

\section{Sources of funding}

University of Brighton Centre for Teaching and Learning Scholarship Grant.

\section{Ethical approval}

University of Brighton's School of Health Sciences Research Ethics Panel.

\section{ORCID}

Sarah-Jane Ryan https://orcid.org/0000-0002-0410-8890

Jane Morris $\quad$ https://orcid.org/0000-0002-0129-9222

\section{References}

Aronin, S., \& Smith, M. (2016, August, 9). One in four students suffer from mental health problems. YouGov. https://yougov.co.uk/topics/lifestyle/articles-reports/2016/08/09/quarter-britainsstudents-are-afflicted-mental-hea

Barrington, K., \& Street, K. (2009). Learner contracts in nurse education: Interaction within the practice context. Nurse Education in Practice, 9(2), 109-118. https://doi.org/10.1016/j.nepr.2008.10.004

Boud, D. (2015). Feedback: Ensuring that it leads to learning. The Clinical Teacher, 12(1), 3-7. https://doi.org/10.1111/tct.12345

Bradbury-Jones, C., Sambrook, S., \& Irvine, F. (2009). The phenomenological focus group: An oxymoron? Journal of Advanced Nursing, 65(3), 663-671. https://doi.org/10.1111/j.13652648.2008.04922.x

Braun, V., \& Clarke, V. (2006). Using thematic analysis in psychology. Qualitative Research in Psychology, 3(2), 77-101. https://doi.org/10.1191/1478088706qp063oa

Chan, S. W.-C., \& Chien W. -T. (2000). Implementing contract learning in a clinical context: Report on a study. Journal of Advanced Nursing, 31(2), 298-305. https://doi.org/10.1046/j.13652648.2000.01297.x

Chipchase, L. S., Buttrum, P. J., Dunwoodie, R., Hill, A. E., Mandrusiak, A., \& Moran, M. (2012). Characteristics of student preparedness for clinical learning: Clinical educator perspectives using the Delphi approach. BMC Medical Education, 12(112). https://doi.org/10.1186/1472-6920-12$\underline{112}$ 
Clouder, L. (2000). Reflective practice: Realising its potential. Physiotherapy, 86(10), 517-522. https://doi.org/10.1016/S0031-9406(05)60985-6

Clouder, L., \& Adefila, A. (2014). The 'Gift Exchange': A metaphor for understanding the relationship between educator commitment and student effort on placement. International Journal of Practice-based Learning in Health and Social Care, 2(2), 54-64. https://publications.coventry.ac.uk/index.php/pblh/article/view/321

Cooper, L., Orrell, J., \& Bowden, M. (2010). Work integrated learning: A guide to effective practice. Routledge.

Creswell, J.W. (2007). Qualitative inquiry and research design (2nd. ed.). Sage.

Cross, V. (1998). Begging to differ? Clinicians' and academics' views on desirable attributes for physiotherapy students on clinical placement. Assessment \& Evaluation in Higher Education, 23(3), 295-311. https://doi.org/10.1080/0260293980230306

Cross, V. (2013). Practice educators in an uncertain world: Still too much to ask? International Journal of Practice-based Learning in Health and Social Care, 1(1), 29-36. https://publications.coventry.ac.uk/index.php/pblh/article/view/255

Cross, V., Moore, A., Morris, J., Caladine, L., Hilton, R., \& Bristow, H. (2006). The practice-based educator: A reflective tool for CPD and accreditation. Wiley.

Dahl-Michelsen, T. (2015). Curing and caring competencies in the skills training of physiotherapy students. Physiotherapy Theory and Practice, 31(1), 8-16. https://doi.org/10.3109/09593985.2014.949946

Dall'Alba, G. (2009). Learning professional ways of being: Ambiguities of becoming. Educational Philosophy and Theory, 41(1), 34-45. https://doi.org/10.1111/j.1469-5812.2008.00475.x

Delany, C., \& Bragge, P. (2009). A study of physiotherapy students' and clinical educators' perceptions of learning and teaching. Medical Teacher, 31(9), e402-e411. https://doi.org/10.1080/01421590902832970

Delany, C., \& Molloy, E. (Eds). (2009). Clinical education in the health professions. Churchill Livingstone.

Department of Health. (2013). Delivering high quality, effective, compassionate care: Developing the right people with the right skills and the right values. UK Department of Health. https://assets.publishing.service.gov.uk/government/uploads/system/uploads/attachment_data/fil e/203332/29257_2900971_Delivering_Accessible.pdf

Equality Act. (2010). http://www.legislation.gov.uk/ukpga/2010/15/contents

Grace, S., \& Trede, F. (2013). Developing professionalism in physiotherapy and dietetics students in professional entry courses. Studies in Higher Education, 38(6), 793-806. http://dx.doi.org/10.1080/03075079.2011.603410

Greene, M. J. (2014). On the inside looking in: Methodological insights and challenges in conducting qualitative insider research. The Qualitative Report, 19(29), 1-13. http://www.nova.edu/ssss/QR/QR19/greene15.pdf

Greenfield, B., Anderson, A., Cox, B., \& Tanner, M. C. (2008). Meaning of caring to 7 novice physical therapists during their first year of clinical practice. Physical Therapy, 88(10), 1154-1166. https://doi.org/10.2522/ptj.20070339 
Griffiths, L., Worth, P., Scullard, Z., \& Gilbert, D. (2010). Supporting disabled students in practice: A tripartite approach. Nurse Education in Practice, 10(3), 132-137. https://doi.org/10.1016/j.nepr.2009.05.001

Hartigan-Rogers, J. A., Cobbett, S. L., Amirault, M. A., \& Muise-Davis, M. E. (2007). Nursing graduates' perceptions of their undergraduate clinical placements. International Journal of Nursing Education Scholarship, 4(1), article 9. https://doi.org/10.2202/1548-923X.1276

Harvey-Lloyd, J. M., Morris, J., \& Stew, G. (2019). Being a newly qualified diagnostic radiographer: Learning to fly in the face of reality. Radiography, 25(3), e63-e67. https://doi.org/10.1016/j.radi.2019.01.007

Health and Care Professions Council. (2018). Standards of education and training. HCPC. http://www.hpc-uk.org/standards/standards-relevant-to-education-and-training/set/

Healey, M., Flint, A., \& Harrington, K. (2014). Engagement through partnership: Students as partners in learning and teaching in higher education. Higher Education Academy. https://www.advancehe.ac.uk/knowledge-hub/engagement-through-partnership-students-partners-learning-andteaching-higher

Hockings, C. (2010). Inclusive learning and teaching in higher education: A synthesis of research. The Higher Education Academy. Retrieved November 5, 2018, from:

www.heacademy.ac.uk/assets/York/documents/ourwork/inclusion/wp/inclusive_teaching_and_ learning in he.doc

Jackson, A. Y., \& Mazzei, L. A. (Eds.). (2009). Voice in qualitative inquiry: Challenging conventional, interpretive and critical conceptions in qualitative research. Routledge.

Keating, J., Dalton, M., \& Davidson, M. (2009). Assessment in clinical education. In C. Delany \& E. Molloy (Eds.), Clinical education in the health professions (pp. 147-172). Churchill Livingstone.

Lindquist, I., Engardt, M., Garnham, L., Poland, F., \& Richardson, B. (2006). Physiotherapy students' professional identity on the edge of working life. Medical Teacher, 28(3), 270-276. https://doi.org/10.1080/01421590600605272

Matheson, R. (2003). Promoting the integration of theory and practice by the use of a learning contract. British Journal of Therapy and Rehabilitation, 10(6), 264-270. https://doi.org/10.12968/bjtr.2003.10.6.13535

McAllister, L., \& Lincoln, M. (2004). Clinical education in speech-language pathology. WileyBlackwell.

Merriam, S.B. (2009). Qualitative research: A guide to design and implementation (2nd ed.). Jossey Bass.

Molloy, E. (2009). Time to pause: Giving and receiving feedback in clinical education. In C. Delany \& E. Molloy (Eds.), Clinical education in the health professions (pp. 128-146). Churchill Livingstone.

Mooney, M., Glacken, M., \& O’Brien, F. (2008). Choosing nursing as a career: A qualitative study. Nurse Education Today, 28(3), 385-392. https://doi.org/10.1016/j.nedt.2007.07.006

Morgan D. L. (1997). Focus groups as qualitative research (2nd ed.). Sage.

Morris, D. (2011). Physiotherapy students' lived experience of formative assessment during practice education [Unpublished doctoral thesis]. University of Brighton. 
Morris, D., \& Turnbull, P. (2006). Clinical experiences of students with dyslexia. Journal of Advanced Nursing, 54(2), 238-247. https://doi.org/10.1111/j.1365-2648.2006.03806.x

Nicholls, D. (2009). Qualitative research: Part one - Philosophies. International Journal of Therapy and Rehabilitation, 16(10), 526-533. https://doi.org/10.12968/ijtr.2009.16.10.44562

Nicholls, D., \& Gibson, B. (2010). The body and physiotherapy. Physiotherapy Theory and Practice, 26(8), 497-509. https://doi.org/10.3109/09593981003710316

Nicholls, D., \& Holmes D. (2012). Discipline, desire, and transgression in physiotherapy practice. Physiotherapy Theory and Practice, 28(6), 454-465.

https://doi.org/10.3109/09593985.2012.676940

Rodger, S., Fitzgerald, C., Davila, W., Millar, F, \& Allison, H. (2011). What makes a quality occupational therapy practice placement? Students' and practice educators' perspectives. Australian Occupational Therapy Journal, 58(3), 195-202. https://doi.org/10.1111/j.14401630.2010.00903.x

Schmitt, J., Akroyd, K., \& Akroyd, L. (2012). Perceptions of physiotherapy students of a person-centred approach in rehabilitation. International Journal of Therapy and Rehabilitation, 19(1), 23-30. https://doi.org/10.12968/IJTR.2012.19.1.23

Smith, M. \& Trede, F. (2013). Reflective practice in the transition phase from university student to novice graduate: Implications for teaching reflective practice. Higher Education Research and Development, 32(4), 632-645. https://doi.org/10.1080/07294360.2012.709226

Thomas, L., \& May, H. (2010). Inclusive learning and teaching in higher education. The Higher Education Academy. https://www.heacademy.ac.uk/system/files/inclusivelearningandteaching finalreport.pdf

Trede, F., Macklin, R., \& Bridges, D. (2012). Professional identity development: A review of the higher education literature. Studies in Higher Education, 37(3), 365-384. https://doi.org/10.1080/03075079.2010.521237

Webster-Wright, A. (2009). Reframing professional development through understanding authentic professional learning. Review of Educational Research, 79, 702-739. https://doi.org/10.3102/0034654308330970

Wenger, E., Trayner, B., \& de Laat, M. (2011). Promoting and assessing value creation in communities and networks: A conceptual framework (Rapport 18). Open University of the Netherlands.

West, M. (2019). The NHS crisis of caring for staff: What do we need to do? The King's Fund. https://www.kingsfund.org.uk/blog/2019/03/nhs-crisis-caring 


\title{
Appendix A
}

\author{
University of Brighton \\ School of Health Sciences \\ Division of Physiotherapy \\ Student Passport
}

Students: Please complete your passport and update it after every placement. You should also discuss it with your personal tutor, particularly during the first completion. A copy MUST be sent to your placement educator (this is in addition to the introductory phone-call/email) not less than 2 weeks prior to placement starting. You should also share it with the visiting tutor for each placement.

\section{Name and year (cohort) of student:}

Student's placement accommodation address:

Student's mobile number:

Alternative form of communication (e.g. landline number):

Name and contact details of next of kin/person to be contacted in an emergency (this is optional):

Their relationship to you:

(Educator: This information is only to be used in the case of an emergency and out of office hours when the university placement staff are unavailable. During office hours please email [contactemail@institution] or telephone [01234 567890] rather than contacting student's next of kin.)

\section{Uni Email contact:}

CSP number: [Chartered Society of Physiotherapy student membership number, i.e. professional body - https://www.csp.org.uk/join-csp/join-student-member]

\section{Use of car whilst on placement: Yes}

No

Personal statement: Please include details of your past experiences, what went well on previous placements, what were your areas of development and a brief introduction to you.

(Educator: There is a placement agreement in place with each practice placement site that confirms that all students are prepared for placement experiences in that there are no changes in their DBS clearance, that they are up to date with both their occupational health and mandatory training. Student: Please complete the next 3 boxes in full and be aware that you may be asked for additional information if required by the placement Trust.)

DBS clearance: [Disclosure and Barring service see: https://www.gov.uk/government/organisations/disclosure-and-barring-service]

\begin{tabular}{|l|l|}
\hline & Date \\
\hline Original clearance received & \\
\hline Self-declaration (year 2) & \\
\hline Self-declaration (year 3) & \\
\hline
\end{tabular}


Occupational health clearance:

\begin{tabular}{|l|l|}
\hline $\begin{array}{l}\text { Occupational health visit and reason (you do not } \\
\text { have to disclose personal information, but be } \\
\text { aware that information sharing is intended to be } \\
\text { supportive) }\end{array}$ & Date \\
\hline Tetanus & \\
\hline Hepatitis B & \\
\hline Poliomyelitis & $\begin{array}{l}\text { Tuberculosis (please note there is an international } \\
\text { shortage of vaccinations currently, Public Health } \\
\text { England 2016 guidelines have assessed health } \\
\text { workers and students as low risk.) }\end{array}$ \\
\hline Rubella & \\
\hline Chicken pox & \\
\hline
\end{tabular}

Mandatory training:

https://elearning.nsahealth.org.uk/local/sfhadmin/login/index.php

\begin{tabular}{|c|l|l|}
\hline Session & Date completed & $\begin{array}{l}\text { Expiry date } \\
\text { (if known) }\end{array}$ \\
\hline 1. Conflict resolution e-learning & & \\
\hline 2. Safeguarding adults level 1 e-learning & & \\
\hline 3. Safeguarding adults level 2 e-learning & & \\
\hline 4. Safeguarding Children level 1 e-learning & & \\
\hline 5. Equality, diversity and human rights - \\
general awareness - e-learning
\end{tabular}


Learning Support Plan (LSP): if you have a LSP in place please include the key details from your LSP and suggested adjustments. All reasonable adjustments must be discussed with the placement team prior to placements.

Placement experiences:

\begin{tabular}{|l|l|l|}
\hline Placement & Type of experience & Dates \\
\hline Pre course work experience & & \\
\hline $\begin{array}{l}\text { Year 1 } \\
\text { MSc: community classroom } \\
\text { experience or } \\
\text { BSc: active student } \\
\text { experience }\end{array}$ & & \\
\hline Placement 1 & & \\
\hline Placement 2 & & \\
\hline Placement 3 & & \\
\hline Placement 4 & & \\
\hline Placement 5 & & \\
\hline
\end{tabular}

Strengths and development needs. Please feel free to discuss with your personal tutor. This should be based on your academic work and the placement assessment forms:

\begin{tabular}{|l|l|l|}
\hline Placement/speciality & $\begin{array}{l}\text { What were identified as } \\
\text { your strengths? }\end{array}$ & $\begin{array}{l}\text { What were identified as } \\
\text { areas for development? }\end{array}$ \\
\hline Placement 1 & & \\
\hline Placement 2 & & \\
\hline Placement 3 & & \\
\hline Placement 4 & & \\
\hline Placement 5 & & \\
\hline
\end{tabular}

Please kindly acknowledge the University of Brighton in any reproductions of this document. 


\section{Appendix B}

\section{Physiotherapy students' and practice educators' experiences of using placements passports: a tool to enhance collaboration on placement: Topic Guide.}

Welcome and thank you for taking part in this study. We would like to start by everyone having the opportunity to introduce themselves.

This study aims to consider the experiences of students and practice educators in using the placement passport.

Please note that this focus is confidential, and we ask you to be as open and honest as you can. Nothing that you say about your experiences or the course will be shared with the course team. You are free to decline answering any question or end your participation in the focus group at any time without providing a reason.

We will now ask you a series of questions exploring your experiences:

- Talk to us about your experiences using the placement passports?

- Can you reflect on how it worked or didn't work for you?

- What do you feel are the benefits for you and your student/practice educator?

- Any challenges for you in using the passport?

- Any other thoughts you would like to add? 